\title{
PROMOTING THE JOY OF TEACHING AND LEARNING IN A DIVERSE WORLD
}

\author{
M. F. Omidire* \\ Department of Educational Psychology \\ http://orcid.org/0000-0002-5784-7734
}

\author{
F. R. Aluko* \\ Unit for Distance Education \\ http://orcid.org/0000-0003-0499-042X
}

\section{R. Mampane*}

Department of Educational Psychology

http://orcid.org/0000-0002-9853-2077

*University of Pretoria

Pretoria, South Africa

\section{ABSTRACT}

Joy is a feeling that goes beyond happiness, and learning at whatever level should evoke joy in both students and teachers if its goals were to be met. However, the joy of learning may sometimes be totally excluded in a diverse world, especially in emerging economy contexts where issues of equality, equity and social justice are more profound. Using qualitative research methods and the theory of change as the theoretical framework, this study attempts to understand how joy can be promoted in learning despite the major complex diversities that often confront education in such emerging economy contexts. Findings indicate that explicit, implicit and hidden curriculum is key to realising the goals of learning. Furthermore, individuals from diverse settings want to be included in their own education and want their identity, culture, language and life experiences to form part of what is being learned. The participants believe that technology is critical to achieving the joy of learning in the $21^{\text {st }}$ century and beyond. Recommendations include redesigning the curricula at various education levels to make it more relevant and inclusive and returning to the emotional aspects of teaching and learning. Higher education institutions have a critical role to play in achieving a paradigm shift in the training of preservice teachers. We advance further areas of research.

Keywords: teaching and learning, joy of learning, diversity, technology

\section{INTRODUCTION}

Learning is a cognitive process, which is transformative, collaborative and interactive. As asserted by Boeree (1998), one would have expected that the ease with which children learn 
would be extended into their adolescence and adulthood. However, the reverse is the case; it appears joy has been taken out of learning. According to Seneechal (2017), joy is not the same as cheer, happiness, or even enjoyment. It does not always manifest itself in smiles and laughter, but it is a happiness that goes beyond regular happiness; it has to do with a quality of perception - of seeing and being seen, of hearing and being heard (Seneechal 2017). We also add that feelings of curiosity, excitement, disturbance and wonder should all be linked to the notion of joy.

Experience has shown that promoting joy in learning must focus on students' readiness to learn, making the subject of learning important, and making it meaningful to students. This can be linked to the social constructivism theory of Vygotsky (1987). He introduced the concepts of scaffolding and the Zone of Proximal Development (ZPD). In learning, ZPD focuses on the role of adults or a more able peer in learning and the interactive and developmental process of learning. Learning is linked to development and growth and curriculum is core to achieving the desired goals of teaching and learning. This article purports that learning is, among others, a process that is self-directed, purposeful, life-long, developmental and not context-bound. Curriculum and pedagogic methodologies drive the goals of learning. If identity and individual differences are not considered, those who are minorities or are different could be deprived of the joy of learning.

One of the ways in which diversity in education could be managed is the use of technology. Ground-breaking technologies have helped to bring to the fore the affordances that Information Communications and Technologies could bring to teaching and learning. Globally, technology-in-education has made it possible to reach millions all over the world irrespective of their context via relevant technology. "The world is a global village" is a common statement that expresses how connected we truly are. However, with this connection comes many complexities, which involve finding our place and voice in the midst of it all. The complexities are particularly a reality in teaching and learning situations where groups are largely diverse. The extent of diversity encompasses a range of features, which include individual identity, creativity, freethinking, experiences of success, and differences in learning and multicultural perspectives. Aside these are other challenges facing teaching and learning, which, according to Osman and Booth $(2014,161)$ include ineffective teacher preparation, issues of teacher identity and teachers' work. The authors assert that the scrutiny regarding education will not go away as stakeholders demand a return on investment.

Using a spiritual metaphor, Davids and Waghid (2019) emphasise teaching and learning should constitute a pedagogic pilgrimage if higher education is to remain responsive to a public good. According to the authors, teaching and learning must be in a continuous state of reflection 
and change while considering that which is intrinsic to students, among others. However, Rantala and Määttä $(2012,87)$, have noted that "in the field of educational psychology, research on feelings is lacking, and the little that does exist has focused more on negative rather than positive feelings". With this article, we aim to add to knowledge on promoting the joy of learning in diverse, multicultural contexts and possibly influence the redirection of preservice teacher education in higher education institutions. Therefore, the purpose of the study was to explore perspectives on how to ensure the joy of learning in a complex diverse world. Our focus was to gain insights into factors that could be employed to ensure that individuals embrace diversity and attain the joy of learning that we all desire, especially in emerging economy contexts where issues of equality, equity and social justice are more profound. The research questions were:

- How can learning with and from others be achieved in a multicultural context?

- How can we promote the joy of learning in the face of diversity?

- How can technology facilitate our efforts to restore the joy of learning?

\section{LITERATURE REVIEW}

There is a dearth of literature on the joy of teaching and learning, a literature search yields very little research on the joy of learning or the joy of teaching. In this section, the focus will be on teaching and learning (which are related to the theories of learning, the process and the output) and the joy of teaching and learning.

Theories of learning focus mostly on an individual's ability to comprehend what is taught and the cognition domain as a key determinant to having the ability to learn. The literature on teaching and learning shows the dependent relationship between the two concepts. Fry, Ketteridge, and Marshall (2008, 3) suggest that, "effective teaching (and supervision, assessment, planning and so on) has to be predicated on an understanding of how students learn; the objective of the activities is to bring about learning, and there has to be insight and knowledge about students' needs for teaching to be successful". Anderman and Dawson (2010) concur that teaching and learning are sciences that address the how of teaching (instructions on how people learn) and the how of learning. Therefore, effective learning is dependent on effective teaching. Learning is an interactive process that brings about change in an individual; it leads to the acquisition of knowledge and to achieving expected learning outcomes (Biggs 1999, 60). Even though there is no one, universally acceptable definition of learning, researchers agree that learning is important (Schunk 2012). Learning outcomes are determined by the following factors: "fixed student-related factors such as ability; teaching-related factors 
such as curriculum, and methods of teaching and assessing; and the approaches to learning that students use while engaging in any particular task to achieve an outcome" (Biggs 1999, 61). In summary, "learning involves change; learning endures over time, and learning occurs through experience" Schunk $(2012,4)$.

The science of learning and teaching is guided by theories. Theories of learning focus on how people learn and serve as indicators for how to teach to facilitate learning. Theories of learning indicate that learning is driven by, for example, behaviourism, cognitive-gestalt and constructivism. The context and process of learning is an important contributor to the individual's cognitive social domain (nurture). When theories of learning focus on the formalised process of learning (curriculum and schooling) in alignment to expected developmental milestones, the context of learning (policies) and access to resources are important. These theories do not focus on the joy of teaching and learning, but there is a reference to motivation theories which are linked to social-cognitive theories.

The overarching question is then, when and how is the joy of teaching and learning realised? Similar to the theories of learning, emotions are resonating from biological, psychological and sociological perspectives (Rantala and Määttä 2012). Joy is an emotion. The joy in teaching and learning is mostly associated with intrinsic motivations (Light 2003; Davids and Waghid 2019). Enjoyment is subjective and an individual experience evidenced in the processes of teaching and learning. Anderman and Dawson $(2010,219)$ define motivation as the process that instigates and sustains goal-directed activities. Accordingly, Bonney and Strernberg $(2011,177)$ declare that intrinsic motivation is "related to the idea of interest, such that individuals who are intrinsically motivated will engage in a task for no other reward than the interest and enjoyment of the activity". Therefore, intrinsically motivated individuals engage in a task for the sake of learning and the joy of it.

The home environment, as a nurturer of learning is important. Learning and literacy begin at home with parents and caregivers who are primary educators. Human beings are relational beings, therefore, teaching and learning are not only an individual cognitive process, but it enhances the social interactions, commitments and collectivistic nature of people. Lave (1996, 156) proposes that the theory of learning has three stipulations, namely: "telos for the changes implied in notions of learning; the basic relation assumed to exist between subject and social world; and mechanisms by which leaming is supposed to take place”. Accordingly, Lave (1996, 156) defines the three stipulations of learning as follows:

"Telos: a direction of movement or change of learning (not the same as goal-directed activity);"

"Subject-world relation: a general specification of relations between subjects and the social world 
(not necessarily to be construed as learners and things to-be-learned);"

"Learning mechanisms: ways by which learning comes about."

The points above suggest that the emphasis on teaching is not only on curriculum and instruction (what is taught) or what teachers can do to affect learning but also on the preservice training teachers receive in higher institutions of learning (Cross 1987). The complexity of teaching and learning is not just in understanding student and teacher interactions or the instructional relationship but also in defining the complementary relationship between the two phenomena. Focusing on teacher training can lead to understanding the following question: What can teachers do to affect joy in learning? The joy in learning is attached and brings about the emotive process of learning. According to Rantala and Määttä $(2012,88)$, the joy of learning can be expressed through emotions and actions as posed in the question: "Could joy offer any significant aid to learning?" Approaching teaching and learning with enthusiasm and confidence brings about enjoyment (Light 2003). The joy of learning is intrinsic and is expressed through the enjoyment of the learning.

\section{PROBLEM STATEMENT AND CONTEXT OF THE STUDY}

South Africa, like many African countries, experiences multiple challenges in its education system such as high student dropout rates, socioeconomic problems, lack of access to higher education, high teacher-student ratio and poorly resourced educational institutions. These adversities affect the joy of learning. Theories of learning confirm that learning is not just a cognitive process, but a behaviourist, social and constructivist process. Learning is a developmental process that leads to outcomes and helps people to achieve their goals. Therefore, learning is self-directed, purposeful, lifelong, and the context of learning is important. Learning brings about behavioural change and requires the individual's active involvement in the process. Educational activities that are of interest, value and relevant to students bring joy in learning (Light 2003). Experience of joy in teaching and learning can lead to successful outcomes.

The study was conducted at the Faculty of Education of a South African public university, which is in an emerging economy context with high levels of inequality and limited access to resources by many of the students. The student and staff population include individuals from other African countries with similar histories and high need contexts.

\section{THEORETICAL FRAMEWORK: THEORY OF CHANGE}

For this study, we have adopted a limited scope of the Theory of Change. According to Turner 
(1982, cited in Connolly and Seymour 2015, 1), all human beings are "theorists insofar that they engage in a mental process by which they develop ideas that allow them to explain why events ought to occur". Although the theory's definition and methodology are fluid because of the flexibility with which practitioners work with it (Vogel 2012, 3), Connolly and Seymour $(2015,1)$ define it as "a predictive assumption about the relationship between desired changes and the actions that may produce those changes". Therefore, as a method, it "explains how a given intervention, or set of interventions, is expected to lead to specific development change, drawing on a causal analysis based on available evidence" (United Nations Development Group $2017,4)$. Among others, the benefits of using the theory include its ability to situate a project in a real-life, provide information regarding the necessity for a change; and the what, why and how of an intervention (De Silva, Lee and Ryan 2015; James 2011, 3).

Though there is no agreement on the basic elements that make up the theory (Vogel 2012), we have identified the following from our perusal of literature (Centre for the theory of change 2018; Clark and Taplin 2012; Vogel 2012): a good situation analysis, ascertaining long-term goals, backwards mapping, linking the prerequisites and recognising your basic assumptions about the context. Others are identifying the relevant interventions, developing indicators and writing up the narrative.

For this study, we have taken advantage of the flexibility of the theory to develop our theory of change regarding how to promote the joy of teaching and learning based on available literature. Laing $(2015,4)$ identifies four approaches to developing a theory of change, which are the deductive, inductive, mental and collaborative models. Of these, we have adopted the deductive model in which theories of change are developed from existing research. In this model, the evidence is gathered "from literature and existing knowledge about how the world works, and simplified into steps of change" (Laing 2015,4). This has enabled us to identify the long-term goals and outcomes of education. From these, we have further developed some assumptions linked to corresponding actions, which we have probed through qualitative research methodology. Therefore, for this article, we have been guided by the following aspects of the theory of change: the desired change, predictive assumptions with the relationship that exists between these and the desired change, and the actions that may bring about the desired change (Connolly and Seymour 2015, 1).

\section{METHODS}

For this study, we have adopted the qualitative research method with a case study design and a focus on higher education institutions. The participants were lecturers and students who worked and studied in the same higher education institution from Botswana (BWA), Cameroon (CMR), 
Ghana (GH), Nigeria (NG), South Africa (SA) and Zimbabwe (ZBW). Ethics clearance was obtained from the institutional committee as part of a larger project. Informed consent letters were given to all participants, and consents forms were signed by them.

An open-ended survey questionnaire was used to explore the participants' perspectives on the joy of learning. The questionnaires were distributed to 125 individuals. Forty-two point four per cent (42.4\%) of the participants completed and returned the questionnaires. The table below shows the participant breakdown.

Table 1: Distribution of participants

\begin{tabular}{|l|c|c|c|c|}
\hline \multicolumn{1}{|c|}{ Participants } & Code & Number sent & Number returned & Percentage \\
\hline Lecturers & L & 8 & 8 & \\
\hline Undergraduates & $\mathrm{U}$ & 12 & 5 & \\
\hline Honours & $\mathrm{H}$ & 40 & 19 & \\
\hline Masters & $\mathrm{M}$ & 50 & 13 & \\
\hline PhD & $\mathrm{P}$ & 15 & 8 & \\
\hline Total & & 125 & 53 & $42.4 \%$ \\
\hline
\end{tabular}

\section{DATA ANALYSIS}

The open-ended survey questionnaires that were returned were divided into sections relating to the research questions. For the first research question, the relevant section of the questionnaire was analysed deductively while, for the other sections, they were analysed inductively through a process of organisation according to groups of participants. The responses were then transcribed, coded and categorised into themes (MacMillian and Schumacher 2014). To make sense of the data and arrive at tangible conclusions, the inductive analysis of data entailed compiling, grouping and interpreting the data (Yin 2016).

The codes for the referencing of participants' quotes are: cohort and department/gender and participant number/country of origin. For example: M-EP/F1/GH would be the participant who is a master's student in the Department of Educational Psychology, female no.1 from Ghana.

\section{FINDINGS}

In this section, we present the findings.

\section{Learning with and from others}

In responding to the research question, "How can learning with and from others be achieved in a multicultural context?" three themes were deduced based on the actual questions on the 
survey. These themes are collaboration, understanding the goals of learning and investigating the role of the curriculum.

\section{Collaboration}

This theme explored the participants' perceptions of the meaning of learning with and from others and how this can be achieved within the context of the study. The participants indicated that learning should be foregrounded in constructivists' ideology, processes and inputs. They reiterated that mutual understanding and opportunities for knowledge creation should be implicit in the teaching and learning environment. In addition, learning has to be viewed as a social activity, with students enabled to learn together and from others using collaborative techniques. "We are able to put our heads together, and we are able to discuss things and participate collaboratively" (M-EP/F1/SA).

"Engaging in a process of sharing information, procedures, strategies, ways of solving problems." (H-P/F2/SA).

"Supporting each other by listening, giving council and being there for your peer." (M-O/F3/SA).

The participants posited that cohesion and common understanding, as well as the ability to view phenomena from different perspectives, are fostered in settings that stimulate students to share relevant knowledge, experiences and skills for problem-solving. Some of the participants believe learning from and with each other means:

"Creating spaces where people feel that their knowledge and unique expertise are valued." (L$\mathrm{EP} / \mathrm{F} 18 / \mathrm{SA})$.

"Work-based learning being and involved in projects and using comparative education as lens. A voluntary process - acquiring more knowledge or skill or insight based on others' input." (P$\mathrm{EP} / \mathrm{M} 5 / \mathrm{NG})$.

"Learning from other can take place incidentally; enquiry-led learning through questioning and observation." P-O/M10/GH.

"Mutual understanding and respect among the participants; peer education, sharing learning spaces." (H-EP/F4/ZBW).

“... feeling comfortable in sharing own views without any fear." (M-LS/F7/SA).

\section{Understanding the goal of learning}

The second theme explored the participants' understanding of what constitutes the goals of learning in a diverse world. The participants stated that the goals of learning include achieving a change in behaviour, knowledge, opinion and skills. The participants also stated that the goals 
of learning are to develop context-specific values and knowledge, to stimulate wisdom and the ability to reflect on opposing views as well as promote mutual understanding. Furthermore, learning should enable, empower and cultivate the aptitude for adaptation and survival in various situations. Other participants linked learning to acquiring an education and being able to apply that education to make a difference, thereby facilitating personal and professional development and empowerment with skills. Also important is the participants' belief that the goal of learning includes alleviating ignorance and prejudice as well as empowering students to become knowledge producers. Additionally, to broaden the worldview to appreciate diversity not to be stereotypical. Below are some of their comments: The goal of learning is to

"... create an ability to critically reflect to stimulate wisdom, to broaden/promote understanding." (L-EP/M2/LE).

"... meet the standards of acquiring relevant knowledge, to instil discipline in the individual and the group and change in behaviour." (L-EP/F20/SA).

"... equip students to be competent citizens, to contribute to the success of the country and to bring transformation." (P-O/M10/GH).

\section{Investigating the role of the curriculum in learning}

Regarding the theme of investigating the role of curriculum in achieving the goals of learning, the participants opined that the curriculum provides a platform for students to engage with content and stipulate minimum outcomes of learning which include knowledge, skills and values. It serves to guide learning such that individuals can achieve the goals they have set. It is also seen as a tool through which transformation can be achieved and support for relevant learning. According to a participant (L-EP/M1/LE), the curriculum

“... provides scope for learning, a plan of what and how to learn ... it provides a planned, organised and outcomes-based instruction for learning, and it provides focus and offers specialised instruction to enable learning."

\section{PROMOTING THE JOY OF LEARNING}

In responding to the second research question, "How can we promote the joy of learning in the face of diversity?" The participants' responses were classified into three categories. The first is culture and identity, the second the multiple pathways to knowledge generation, and the third is acceptance and respect.

\section{Culture and identity}

Preliminary results indicate that individuals from diverse settings want to be included and want 
their identity, culture, language and life experiences to form part of; and be showcased in their learning. The respondents expressed frustration at the inability of their curriculum to reflect their culture and identity. Their home languages should be incorporated and not expunged from the learning activities, as is often the case. There is value in cultural capital, and the histories and local literature of students need to be portrayed and taught side by side with those of other countries being taught. Learning should be contextually meaningful and appropriate. The participants expressed a sense of being invisible in the learning environment - an unspoken notion of invisibility and not having a say in the process of learning, of not being seen or heard. Being able to see themselves in and identify with what is taught and expected in learning resonate with students who can identify with learning content in a more meaningful way.

\section{Multiple pathways to knowledge generation}

The participants opined that one of the things that strip away the joy of learning is when one way of knowing is espoused as the correct and only way learning can or should be achieved. They believed that the joy of learning could be ensured if teachers take into account the diversity of their students as the students are thus able to learn from each other. Individuals have various skills sets, strengths and experiences that they bring to the learning environment. Recognising and leveraging these strengths ensures that learning is engaging and collaborative. The participants believe that current teaching and learning models depend mainly on who the teacher is and are not taking into account diversity in teaching and learning environments, diminishing the joy of learning. The role of individual differences in the teaching and learning environment needs to be explored. The participants believe that there needs to be a paradigm shift from the negative view of diversity to fully actualise the joy of learning in post-colonial Sub-Saharan African countries. A participant laments,

\footnotetext{
"A challenge here is that we need marks to determine whether we pass or fail modules, however, just because of their different ways of learning or thinking, students are given less marks and are therefore forced into 'the right way' of thinking/learning so that they can pass. I think our current education system does not produce/allow for joy in learning." (M-EP/F1/SA)
}

\section{Acceptance and respect}

According to the participants, diverse settings provide an opportunity for all students to be accepted and respected. This is often not the case as those that are different are often labelled and made to feel inferior. The participants believed that learning should be humanised through inclusion. 


\section{STRATEGIES FOR PROMOTING THE JOY OF LEARNING}

In response to the question, "how can we promote the joy of learning?" the participants reiterated that multiple ways of thinking about learning and learning the same information should be an integral part of the teaching and learning process. They believed that students working together and sharing ideas with their peers is a more effective way of learning and ensuring that there is joy in the process.

The participants suggested a subject area or learning content could be approached in different ways and taught, using various approaches that would be meaningful to the students. They believed that embracing all forms of diversity, including cultural, linguistic and learning diversity, is beneficial. They asserted they can learn more from shared experiences than from being passive receptors of information. This additionally means that the content of learning has to resonate with the lived experiences of the students to promote the joy of learning.

Non-traditional pedagogies and incorporation of real-life circumstances should be used, and non-formal settings planned into learning experiences. Furthermore, the participants stated that providing enabling environments, where everyone is valued as an equal contributor and where there is interactive and collaborative learning, will go a long way in ensuring that there is joy in learning. The participants believed that advances in technology could contribute in terms of the processes involved in promoting the joy of learning.

\section{THE ROLE OF TECHNOLOGY}

In relation to the question, "How can technology facilitate our efforts to restore the joy of learning?" the participants unanimously concurred that technology has a crucial role to play in promoting the joy of learning. A comment from a participant buttresses this:

"We live in a tech-savvy world, and the visual stimulation in media may make learning more joyful." (H-EP/F15/SA)

Another enthused

“... it can restore the joy of learning ... it can be used in fun and interactive ways, and this creates joy.” (H-EP/F10/SA).

The participants' use of technology incorporates social media and other applications that currently exist. According to a participant,

"Social media drives our world today, so technology plays a mammoth role in everything we do. 
Students can present learning content in ways that it would interact on daily basis instead of the traditional hard copy.” (M-EP/F16/SA)

Regarding its value, some of the participants had this to say:

"Technology can make learning more accessible to people e.g., an educational video on a screen can educate a lecture hall of hundreds of people, fun learning games, iPad games can engage people, especially children by encouraging them to learn ... it can appeal to people with different learning preferences e.g., sound clip for an auditory learner or a video for a visual learner does making learning more engaging and relevant." (H-EP/F12/SA)

"Technology has made our world smaller we can use technology to look at how others are restoring the joy of learning." (H-EP/F14/SA)

"Technology is interactive and it leads to experiences it can be a support." (H-EP/F10/SA)

The participants however, reiterated that the rising cost of education is a hindrance to the attainment of the joy of learning. According to M-EP/F1/SA, "The cost of getting a good education is taking away the joy of learning."

Another one commented "... in order to accommodate all students and their way of learning and thinking. However, there needs to be greater investment into the current structures for e-learning." (M-EP/F1/SA)

\section{LIMITATIONS OF STUDY}

The main limitation of the study is that primary educators, such as parents and caregivers, were not included in the study. In addition, the majority of participants were female, and the focus was solely on formal learning in a higher institution of learning.

\section{DISCUSSION OF FINDINGS WITHIN THE AMBIT OF THEORY OF CHANGE}

As earlier indicated, we have adopted the theory of change, which we have deductively developed for this study. This has enabled us to advance our theory for promoting the joy of learning and teaching from existing research (Laing 2015, 4), allowing us to provide reasons for the desired change, and how such change can be achieved (Connolly and Seymour 2015, 1).

Joy is an emotion. Literature (Tyng et al. 2017) describes emotions as being ubiquitous and having a crucial role to play in human cognitive processes. This makes school a community that powerfully affects the manifestation of emotions, thus making it a well-situated context for research on this field (Rantala and Määttä 2012). The feedback from the participants of this study, regarding how joy can be promoted in teaching and learning suggests this emotion may be lacking in the school context. Echoing Rantala and Määttä's (2012) thoughts and Davids and Waghid's (2019) emphasis on teaching and learning being a pedagogic pilgrimage with 
intrinsic value, one wonders why emotions have traditionally been kept distinct from learning for a long time.

The long-term goal of education in this new dispensation is geared towards achieving the "education that encourages changes in knowledge, skills, values and attitudes to enable a more sustainable and just society for all", popularly known as Education for Sustainable Development (ESD) (Leicht, Heiss and Buyn 2018, 7). This goal tallies with that identified by the participants in this study. Although ESD has the lofty aims of empowering and equipping "current and future generations to meet their needs using a balanced and integrated approach to the economic, social and environmental dimensions of sustainable development" (Leicht, Heiss, and Buyn 2018, 7), Rantala and Määttä $(2012,88)$ stress, "Education does not aim at transforming all students alike." Rather, according to the authors, "education aims at welding different temperaments in such a way that every student can learn and work at school" (Rantala and Määttä 2012, 88). We argue the inability of an education system, (irrespective of the context), to carry out this task successfully, takes away the joy of teaching and learning. The clarion call and suggestions for "educational change and reformation in a contemporary and fast-paced world are inevitable" with stakeholders' "concern about the significant disparity between what occurs in the classroom and what occurs in real-life contexts" (Crawford 2017, 195).

Participants in this study unanimously agreed that one of the ways to promote the joy of learning and teaching is to acknowledge that there are multiple ways of thinking, thus necessitating multiple ways of teaching. There is ample evidence in research that neither "teacher-centric" nor purely "student-centred" teaching helps the students to learn effectively (Bidabadi et al. 2016; Northedge 2003; Rantala and Määttä 2012; Seneechal 2017). Reasons for advocating for a change in learning and teaching approaches are closely linked to change in student nature and demography, coupled with the need to get students ready for life and work (Masters 2015; Zolob 2014).

According to the participants in this study, to promote joy in learning, it is also necessary that the content of learning (curriculum) should resonate with the lived experiences of the students, which agrees with Rantala and Määttä's $(2012,100)$ view that the "joy of learning is context-bound". Therefore, scholars (Deng 2018; Jansen and Van der Merwe 2015; Northedge 2003; Villegas and Ciotoli 2015) advocate Social Constructivism that encourages the sociocultural nature of learning and teaching, helping students to reconfigure what they already know about the subject matter, while the teacher links the content with student's personal and cultural context. Hence, the teacher's responsibility is to encourage and guide the discussion that results in generated knowledge (Jansen and Van der Merwe 2015). One of the strong points 
of the theory of change is that it takes into account the context of a project (Laing 2015). This helps us not to see education as being limited to the four walls of a classroom, but to give due respect to indigenous knowledge, thereby promoting its future (UNESCO 2013, 18). It is evident that teachers' ability to strike a balance inevitably depends on the emphasis placed on this by higher education institutions during preservice training and subsequent teacher professional development engagements. Achieving a shift requires a concerted effort involving teacher training institutions.

Despite the joy that comes from working alone (Seneechal 2017), participants in this study indicated that collaboration and sharing with others also promote the joy of learning and teaching, which we have linked to their views on the need to embrace all forms of diversity. There are major aspects of complex diversities that often confront education in emerging economy contexts where issues of equality, equity and social justice are more profound. Kuchah (2018) asserts that as a result of this, a huge amount of education in the world today takes place in situations that are far from the ideal world of pedagogical excitement. According to ClaytonPedersen, O’Neill and McTighe Musil (2009, 6, cited in Hanesworth 2015), “diversity refers not to the presence of difference in student demographics or course content, but to the act and process of engaging those differences in an intentional, purposeful manner". Therefore, according to Hanesworth (2015), "Embedding equality and diversity in the curriculum is the creating of learning, teaching and assessment environments and experiences that proactively eliminate discrimination, promote equality of opportunity and foster good relations in a manner that values, preserves and responds to diversity". We cannot but agree with the author "teachers need to develop equality and diversity competence". This should go beyond adding a course or two on diversity in the teacher education curriculum, but rather developing a coordinated approach to rethinking the teacher education curriculum for diversity (Villegas and Ciotoli 2015).

Recognising the diversity in a classroom helps us to take cognisance of others' culture and identity, accept them, and build respect and human dignity, which the participants cited as a means of promoting the joy of learning and teaching. Though the economic value of education is important, it is necessary to rethink, rediscover and reaffirm the "humanistic vision of education for the 21st century" (UNESCO 2013, 17). Students need an enabling environment where everyone is valued as an equal contributor to learn, which tie in with the participants' view on recognising multiple pathways to knowledge generation. This leads to "a sense of pride, ownership, and connectedness" for students (Zolob 2014, 56). In such a space, there is freedom (Rantala and Määttä’s 2012), which Briggs (2015) described as giving students choices within limits set by a teacher. 
Lastly, in our quest for the joy of learning and teaching, the participants acknowledged the contributions, which advances in technology can offer to the field of education. This resonates with scholars' opinion (Bates 2015; Cape Digital Foundation 2017; De Bruyckere, Kirschne, and Hulshof 2016; Heick 2017; Masters 2015) that such affordances include communication, personalising diverse teaching and learning tools, the honing of research skills among students, and individualised and collaborative learning among teachers and students. Oosthuizen (2016) has described the $21^{\text {st }}$ century student as a "screen generation" because "they are so much more visually oriented than any generation before them", which comes with its positives and negatives. Nonetheless, this does not mean that all students fall in the same category. For instance, in South Africa and other similar developing contexts, challenges with students' and teachers' lack of technological skills, bandwidth and cost of internet access (that adds to the cost of education) are a reality, and they remain persistent (Mnyanyi and Mbwette 2011; Oosthuizen 2016). Because technology in education is here to stay, scholars have propounded some solutions, which include: the need for the field of education to stop seeing technology as "chrono-centric", in which a person sees his own era or time in history as the most important or the only one that matters (Mishra et al. 2012, 14). Also, to rather develop “technology-mediated professional learning" (Gibson and Brooks 2013, 1064) to assist teachers in understanding the "different ways that technology can represent content, and recognise how the content synchs (or does not synch) with possible teaching approaches” (Mishra et al. 2012, 14). Additionally, for students to "develop capabilities in using ICT in a range of contexts and for a diversity of purposes", and "to gain confidence in learning to cope with rapid changes in the evolution of technology" (Crawford 2017, 197); and to recognise the "dangers of a digital environment" that raises the issues of cyber-bullying and cyber-security (Crawford 2017, 197).

In agreement with Mnyanyi and Mbwette (2011, 9-10), we argue that irrespective of the affordances that technology has to offer, teachers and students are frustrated and demoralised in the face of "lack of technology skills, poor school/classroom infrastructure, relevance of the curriculum, and reliability and availability of ICT resources and services". However, the authors were quick to add teachers' need to change their unwillingness to work with technology because the innovativeness, which should be part of the characteristics of the 21 st century teacher, is impossible without being conversant with technology (Mnyanyi and Mbwette 2011, 11).

\section{CONCLUSION}

For joy to be promoted in learning and teaching, it is necessary for the education system to align itself to the realities of the 21 st century and, in addition, ensure that the curricula are redesigned 
at various levels for more relevance and inclusion. Our view in this study is that there is the need to re-visit the emotional aspect of teaching and learning to restore joy. This invariably means teacher-training institutions need to further focus on the development of teachers' skills to incorporate the human component of teaching and learning. We cannot but agree with Kucha (2018) and Davids and Waghid (2019) that effective teachers are also emotional teachers (with a human face) necessitating more focus on that which is intrinsic to the learners. The realities of the rapid changes being experienced in the world, which include the change in students' demography and nature, and diversity with emphasis on the need to eradicate inequality, cannot be ignored. Others include technology affordances, and what research persistently proves about how best to learn. Our study has suggested ways in which joy can be promoted in learning and teaching, however, in agreement with scholars (Rantala and Määttä 2012; Zolob 2014), we agree that this field needs further investigation and believe that teachers that promote joy in learning will invariably experience the joy of teaching.

\section{REFERENCES}

Anderman, E. M. and H. Dawson. 2010. "Learning with motivation." In Handbook of research on learning and instruction, ed. R. E. Mayer and P. Alexander, 219-241. Routledge, NY, New York.

Bates A. W. 2015. "Teaching in a digital age: Guidelines for designing teaching and learning." Vancouver, Canada: Tony Bates Associates Ltd. https://teachonline.ca/sites/default/ files/pdfs/teaching-in-a-digital-age_2016.pdf. (Accessed 5 January 2019).

Bidabadi, N. S., A. N. Isfahani, A. Rouhollahi, and R. Khalili. 2016. "Effective Teaching Methods in Higher Education: Requirements and Barriers." Journal of Advances in Medical Education \& Professionalism 4(4): 170-178.

Biggs, J. 1999. "What the student does: Teaching for enhanced learning." Higher Education Research \& Development 18(1): 57-75.

Boeree, C. G. 1998. “Teaching, Learning, and the Phenomenology of Meaning.” Journal of Professional Studies 15: 1991. http://webspace.ship.edu/cgboer/meaning.html. (Accessed 5 January 2019).

Bonney, C. R. and R. J. Sternberg. 2011. "Learning to think critically". In Handbook of research on learning and instruction, ed. R. E. Mayer and P. Alexander, 166-196. Routledge, NY, New York.

Briggs S. 2015. "How to bring the joy back into learning." https://www.opencolleges.edu.au/informed/ features/bringing-the-joy-back-into-learning/. (Accessed 5 January 2019).

Cape Digital Foundation. 2017. "The role of ICT in the decolonisation of South African university curricula - technology is the key." http://digitalfoundation.org.za/role-of-ict-in-decolonisationsouth-african-university-curricula/. (Accessed 5 January 2019).

Centre for the theory of change. 2018. "What is Theory of Change?" https://www.theoryofchange.org/ what-is-theory-of-change/. (Accessed 5 January 2019).

Clark, H. and D. Taplin. 2012. Theory of Change Basics: A Primer on Theory of Change (PDF). New York: Actknowledge.

Clayton-Pedersen, A. R., N. O’Neill, and C. McTighe Musil. 2009. "Making excellence inclusive: A framework for embedding diversity and inclusion into college and universities' academic excellence mission." Association of American Colleges and Universities. http://citeseerx.ist.psu.edu/viewdoc/summary. https://doi.org/10.1.1.179.2202.

Connolly, M. R. and E. Seymour. 2015. "Why theories of change matter." Wisconsin Center for 
Education Research, Working Paper No. 2015-2). http://www.wcer.wisc.edu/publications/ workingPapers/papers.php. (Accessed 5 January 2019).

Crawford, R. 2017. "Rethinking teaching and learning pedagogy for education in the twenty-first century: Blended learning in music education." Music Education Research 19(2): 195-213. https://doi.org/10.1080/14613808.2016.1202223.

Cross, K. P. 1987. "Teaching for learning.” AAHE Bulletin 39(8): 1-6. https://files.eric.ed.gov/fulltext/ ED283446.pdf. (Accessed 5 January 2019).

Davids, N. and Y. Waghid. 2019. Teaching and learning as a pedagogic pilgrimage. London: Routledge.

De Bruyckere, P. A., P. A. Kirschne, and C. D. Hulshof. 2016. "Technology in education: What teachers should know." American Educator 40(1): 12-18.

De Silva, M., L. Lee, and G. Ryan. 2015. "Using Theory of Change in the development, implementation and evaluation of complex health interventions: A practical guide." http://www.mhinnovation. net/sites/default/files/downloads/resource/MHIN\%20ToC\%20guidelines_May_2015.pdf.

Deng, Z. 2018. "Rethinking curriculum and teaching." Oxford Research Encyclopaedia, Education. DOI:10.1093/acrefore/9780190264093.013.55.

Fry, H., S. Ketteridge, and S. Marshall. (Ed.). 2008. A handbook for teaching and learning in higher education: Enhancing academic practice. New York: Routledge.

Gibson, S. and C. Brooks. 2013. "Rethinking 21st Century Professional Development." Literacy Information and Computer Education Journal (LICEJ) 4(2): 1064-1073.

Hanesworth, P. 2015. Embedding equality and diversity in the curriculum: A model for learning and teaching practitioners. York: Higher Education Academy

Heick, T. 2017. "How Teaching Is Changing: 15 Challenges for the 21st Century Teacher." https://www.teachthought.com/the-future-of-learning/how-teaching-is-changing/ (Accessed 5 January 2019).

James, C. 2011. "Theory of Change Review: A report commissioned by Comic Relief." Comic Relief, London. http://www.theoryofchange.org/wp-content/uploads/toco_library/pdf/James_ToC.pdf. (Accessed 5 January 2019).

Jansen, C. and P. van der Merwe. 2015. "Teaching Practice in the 21st Century: Emerging Trends, Challenges and Opportunities." Universal Journal of Educational Research 3(3): 190-199. https://files.eric.ed.gov/fulltext/EJ1056080.pdf.

Kuchah, K. 2018. "Early English medium instruction in Francophone Cameroon: The injustice of equal opportunity." System 73: 37-47.

Laing, K. 2015. "Theory-based methodology: Using theories of change for development, research and evaluation." In Research Centre for Learning and Teaching, Newcastle University, ed. K. Laing and L. Todd, 4. http://www.bredeschool.org/sites/default/files/theoryofchangeguide \%282\%29.pdf. (Accessed 5 January 2019).

Lave, J. 1996. "Teaching, as learning, in practice." Mind, Culture, and Activity 3(3): 149-164.

Leicht, A., J. Heiss, and W. J. Buyn. 2018. "Introduction". In Issues and trends in education for sustainable development, ed. A. Leicht, J. Heiss, and W. J. Buyn, 7-9. UNESCO: Paris, France.

Light, R. 2003. "The joy of learning: Emotion and learning in games through TGfU." New Zealand Physical Educator 36(1): 93-108.

MacMillian, J. and S. Schumacher. 2014. Research in Education Evidence-Based Inquiry. $7^{\text {th }}$ Edition. England: MyEducationLab Series. London: UK: Pearson Education Limited.

Masters, G. 2015. “'Big five' challenges in school education.” Australian Council for Educational Research. https://www.teachermagazine.com.au/columnists/geoff-masters/big-five-challengesin-school-education. (Accessed 5 January 2019).

Mishra, P., D. Henriksen, K. Kereluik, L. Terry, C. Fahnoe, and C. Terry. 2012. "Rethinking Technology and Creativity in the $21^{\text {st }}$ Century: Crayons are the Future." TechTrends 56(5): 13-16. 
Mnyanyi, A. and T. S. A. Mbwette. 2011. "Managing 21st Century Quality Teacher Education in Developing Countries: Prospects and Challenges." International Journal of Excellence in Education 4(2): 1-13.

Northedge, A. 2003. "Rethinking Teaching in the Context of Diversity." Teaching in Higher Education 8(1): 19-32. https://doi.org/10.1080/1356251032000052302.

Oosthuizen, A. 2016. "Characteristics of $21^{\text {st }}$ century learners and the challenges they cause teachers." Onderwys (ATKV Educational Newsletter) 10: 1-2.

Osman, R. and S. Booth. 2014. "A research base for teaching in primary school: A coherent scholarly focus on the object of learning." South African Journal of Childhood Education 4(3): 159-173. http://www.scielo.org.za/pdf/sajce/v4n3/11.pdf. (Accessed 5 January 2019).

Rantala, T. and K. Määttä. 2012. "Ten theses of the joy of learning at primary schools." Early Child Development and Care 182(1): 87-105. https://doi.org/10.1080/03004430.2010.545124.

Seneechal, D. 2017. "What is joy, and what is joy in learning?" https://dianasenechal.wordpress. com/2014/03/31/what-is-joy-and-what-is-joy-in-learning/. (Accessed 5 January 2019).

Schunk, D. H. 2012. Learning theories an educational perspective. $6^{\text {th }}$ Edition. New York, NY: Pearson.

Turner, J. H. 1982. The structure of sociological theory. $3^{\text {rd }}$ Edition. Homewood, IL: Routledge.

Tyng, C. M., H. U. Amin, M. N. M. Saad, and A. S. Mali. 2017. "The Influences of Emotion on Learning and Memory." Frontiers in Psychology 8: 1454. https://doi.org/10.3389/fpsyg.2017.01454.

United Nations Development Group (UNDG). 2017. "Theory of Change.” https://undg.org/wp-content/ uploads/2017/06/UNDG-UNDAF-Companion-Pieces-7-Theory-of-Change.pdf. (Accessed 5 January 2019).

UNESCO. 2013. "Rethinking Education in a Changing World." https://unesdoc.unesco.org/ark:/48223/ pf0000224743.

Villegas, A. M. and F. Ciotoli. 2015. "Rethinking the Teacher Education Curriculum for Diversity." https://www.ed.ac.uk/files/atoms/files//villegas.ciotoli_powerpoint_presentation_final.pdf. (Accessed 5 January 2019).

Vogel, I. 2012. "Review of the use of 'Theory of Change' in international development." https://assets.publishing.service.gov.uk/media/57a08a5ded915d3cfd00071a/DFID_ToC_Review _VogelV7.pdf. (Accessed 5 January 2019).

Vygotsky, L. 1987. Zone of Proximal Development. Mind in society: The development of higher psychological processes, 52-91. Cambridge, MA: Harvard University Press.

Yin, R. K. 2016. Qualitative Research from Start to Finish. $2^{\text {nd }}$ Edition. New York: The Guilford Press.

Zolob, T. 2014. "Student Engagement: Experiencing the Joy of Learning through, Learning in Depth." Dissertation, Master of Education in Educational Leadership. Vancouver Island University. 